\title{
Analysis of Differentiation of Regions in the Conditions of Sustainable Development
}

\author{
Margarita Bykova*, Sergey Grachev, and Oleg Donichev \\ Vladimir State University named after A.G. and N.G. Stoletovs, Vladimir, Russia
}

\begin{abstract}
This article is devoted to the analysis of the factors aimed at ensuring the sustainability of development, as well as certain markers of the presence of the stable development of the Russian Federation regions. As part of the work, it is planned to analyze the relationship of digital development in the country and its effective effects for the process of interregional differentiation in modern conditions of a prolonged economic crisis, aggravated by an unfavorable epidemiological situation. In this case, particular importance should be given to the analysis of the ecological component as a factor that predetermines the possibility of the development and implementation of certain technologies. Due to the dynamic assessment of the decoupling effect, the differentiation of regions is assumed, the analysis of the tendency towards a decrease in the inconsistency of the development models of territories. Herewith, special attention is focused on the factor of a potential further decrease in differentiation based on an increase in the sustainability of economic and environmental development processes.
\end{abstract}

\section{Introduction}

Until recently, the interpretation of the category of sustainable functioning of the socialand-economic system was not completely complete. Currently, the sustainable development should combine the harmonization of social, economic and environmental components and have a focus on meeting the needs of both current and future generations. [1].

These requirements are becoming a defining imperative in the context of a protracted economic crisis, complicated by negative trends caused by the pandemic. Restoring the stable functioning of the economy, confirmed by the consistent growth of the country's Gross Domestic Product (GDP) and Gross Regional Product (GRP), should become the main task that may be provided by innovative developments and digital technologies.

Thus, the hypothesis of this paper may be the assumption that there is a relationship between the digitalization process and its consequences and interregional differentiation.

The aim of the study is to form a toolkit for analyzing interregional differentiation in the context of digitalization in order to ensure sustainable development.

The object of the research is the Russian Federation constituent entities, and the subject is their integrative differentiation within the framework of the development of a digital society.

\footnotetext{
${ }^{*}$ Corresponding author: margarita93@bk.ru
} 
Meanwhile, in recent years, the share of regions that are implementing the model of sustainable development has been decreasing against the background of declining rates of economic growth. This process is accompanied by an increase in the consumption of resources of the raw materials sector and environmental pollution [2].

Herewith, the spatial structure of the country's economy was deformed, followed by the aggravation of significant problems that hinder the sustainable development of the Russian Federation constituent entities, among which the leading position is occupied by intraregional differences in social-and-economic parameters [3].

It should be noted that ensuring the economic growth of regions is an important condition for their sustainable development. However, 50 regions failed to cope with the task of doubling the GRP in Russia set in the early 2000s. Moreover, the leading regions developed more and more actively, while the outsiders, on the contrary, weakened, since the factors of regional development remained unchanged [4].

Despite the recognition of the GDP indicator in Russia as a measure of the functioning efficiency, foreign scientists believe that this indicator contributes to the growth of inequality, and it itself does not reflect the quality of economic growth [5].

Herewith, the more stringent environmental standards create conditions for eliminating inequality in the development of territories, since it forces us to look for ways to increase competitiveness through the development and implementation of environmental innovations [6]. Herewith, the conducted empirical studies confirm the higher economic efficiency of the most developed countries and regions [7].

However, the greatest efficiency from the standpoint of sustainable development of territories is achieved by their innovative focus and digitalization of the economy.

Herewith, the formation of a sustainable direction for the development of territories is in unity with the ability of enterprises to create, develop and implement innovations and digital products. [8].

Among the regional factors that form the digital environment in them, one may designate the factor of uncertainty, which may be present at different levels in various aspects [9]. Herewith, the influence of this factor in different regions is ambiguous, which continues to contribute to the growth of differentiation of territories by the level of digital development.

In addition, in these conditions, the availability of specialized knowledge in the management environment of both existing and emerging IT companies is of great importance [10]. Herewith, foreign scientists argue that it is the knowledge generated by large capitals, universities, state research institutes, etc. that serve as the main sources of new business ideas, which are then transformed into regional enterprises. Herewith, an essential role is played by existence of large and saturated labor market [11]. In the formation of the digital sustainability of regions, a special role is played by knowledge related to a fundamentally higher level, discoveries in the field of science, technology, digital innovations, which, in any case, are successful only on the basis of professionally formed human capital with accompanying competencies. It is this capital that, due to the transformation of the modern labor market, acquires decisive importance [12].

Therefore, the importance of the formation of a large saturated labor market for sustainable development in the context of digitalization is increasing many times over. The consequences of active digitalization include the partial release of employed personnel in certain areas due to the reduction in the number of jobs due to the introduction of services and technologies. [13].

The creation and maintenance of sustainable functioning of a saturated labor market in the context of digitalization is a global problem. Therefore, it is noted that with the reduction of jobs as a result of the introduction of digital technologies in innovative firms, this process is less painful. This is due to the fact that innovative activity and retraining of 
personnel have a positive effect on employment, and creative entrepreneurship opens up opportunities for activating the labor market [14]. Herewith, this circumstance may adversely affect the development of new industries in regions with a predominance of the manufacturing industry [15].

Herewith, it should be noted that the basis for the implementation of sustainable socialand-economic development is not only the economic system, but also, to a large extent, the enterprise itself. [16].

Quality engineering in the context of digital transformation is emphasized in various social-and-economic systems. In all cases, the main task of engineering seems to be the need to ensure the sustainability of the enterprise development and the implementation of various options for its transformation in new conditions [17].

The sustainability of the enterprise in the implementation of the digital transition obliges the management of the company to master new management practices, manifested in the form of digital products, business models and processes, etc. [18].

Based on this, the management of information technology by the management of the company should be transformed from a business support function into a tool for increasing production efficiency and a driver of innovation and the introduction of digital technologies [19].

Overcoming these "features" is important because it depends on them whether a state will be reached where information technologies may be a source of sustainable development [20].

These problems naturally lead to the solution of the problem of close interaction of enterprises, especially from manufacturing industries with a variety of stakeholders around them, in order to ensure a high level of compatibility of products and their elements in complex systems. Therefore, for business and the state, the standardization of "smart digital" production comes to the fore [20].

One of the ways to standardize digital production is a new scientific direction related to the creation of so-called digital twins or copies of industrial enterprises or financial corporations [21].

Despite the fact that the concept of digital twins is a relatively recent development, there is research that deepens it. Within their framework, the opinion is expressed that the design of such models should be based on the use of simulation methods [22].

Herewith, universities are becoming increasingly important in the processes of sustainable regional social-and-economic development. Their influence is not limited to scientific research and educational activities. Large academic organizations, being the core of innovation ecosystems, directly influence production through the registration of patents and utility models, software development and the development of knowledge-intensive entrepreneurship [23].

Herewith, sustainable regional development is even more based on the digital space of municipal authorities and enterprises located on their territory. Herewith, a special place in this activity is occupied by the task of creating conditions for the transition to egovernment. However, due to the modest financial capabilities of many municipalities, web resources objectively cannot match the level of federal and regional Internet portals [24].

And, nevertheless, the formation of a digital economy contributes to the transformation of production processes and forms of interaction between economic agents with the aim of sustainable development of regions. [25].

In addition, in the context of digitalization, the specialization of regions is significantly increasing, which ensures the dynamics of sustainable territorial social-and-economic development [26]. Moreover, such dynamics change the structural component of economies, supporting the evolution of development and affecting the well-being of the population. 
Herewith, it is quite obvious that the greatest influence on the sustainable development of the subjects of the federation in these conditions is exerted by the industrial orientation of the economy, which primarily contributes to the achievement of the fastest and most sustainable economic growth, creating additional jobs and increasing the economic activity of the population [27].

It should also emphasize the role of digital innovations, the latest technologies, which increasingly depend on the rationality of their use [28].

Thus, the concept of sustainable development in modern conditions of the active course of digitalization processes acquires a number of features. In addition to the environmental component, it should be noted an increase in the intensity of the use of network resources and changes in the structure of the employed. Accordingly, the cumulative analysis of these aspects is a very topical issue.

\section{Research Methodology}

Pursuant to the study purpose, the task is to form a toolkit for analyzing the differentiation of regions in the identified areas.

The formed goal becomes possible to achieve by calculating the decoupling effect in dynamics. This effect consists in the discrepancy or mismatch in the rates of economic growth of the social-and-economic system, on the one hand, and resource consumption and negative impact on the environment, on the other hand [29]. As a rule, it is accepted to allocate the resource decoupling and the impact decoupling [30].

The resource decoupling assumes a decrease in the volume of primary resources involved per unit of the effect obtained. This aspect indicates an increase in resource efficiency and, accordingly, a decrease in the material consumption of production. In other words, the impact decoupling implies a decrease in the negative impact on the environment while simultaneously increasing production volumes. This effect may be assessed by formula (1):

where $\mathrm{t}$ - time span;

$$
D_{t}=1-\frac{K_{t+1} / Y_{t+1}}{K_{t} / Y_{t}}
$$

$\mathrm{K}$ - negative environmental impact;

$\mathrm{Y}-$ an indicator of the economic result of the functioning of the system.

However, considering these features within the digital economy of the region, this formula may be modernized without changing the semantic load:

where $\mathrm{t}$ - time span;

$$
\mathrm{d}_{\mathrm{ti}}=\left(1-\frac{\mathrm{K}_{\mathrm{t}+1, \mathrm{i}} / \mathrm{Y}_{\mathrm{t}+1, \mathrm{i}}}{\mathrm{K}_{\mathrm{t}, \mathrm{i}} / \mathrm{Y}_{\mathrm{t}, \mathrm{i}}}\right) \times\left(1-\frac{\mathrm{G}_{\mathrm{t}+1, \mathrm{i}} / \mathrm{Y}_{\mathrm{t}+1, \mathrm{i}}}{\mathrm{G}_{\mathrm{t}, \mathrm{i}} / \mathrm{Y}_{\mathrm{t}, \mathrm{i}}}\right) \times\left(1-\frac{\mathrm{H}_{\mathrm{t}+1, \mathrm{i}} / \mathrm{Y}_{\mathrm{t}+1, \mathrm{i}}}{\mathrm{H}_{\mathrm{t}, \mathrm{i}} / \mathrm{Y}_{\mathrm{t}, \mathrm{i}}}\right)
$$

$\mathrm{i}$ - region;

$\mathrm{K}$ - negative impact, expressed in the volume of emissions of pollutants into the air from stationary sources;

$\mathrm{G}$ - the number of crimes in the economic sphere;

$\mathrm{H}$ - number of the unemployed;

$\mathrm{Y}$ - indicator of economic result of functioning of the region.

Considering that the meaning of the changed formula does not change, the accepted interpretation is also preserved, in which a negative value indicates the absence of a decoupling effect, and a positive value indicates its presence. The latter testifies to the 
difference between the trends of economic development and anthropogenic impact: an increase in value added is accompanied by a decrease in the negative burden.

The second component of decoupling, reflecting the effect of exposure, is estimated by the formula (3):

$$
\mathrm{E}_{\mathrm{t}, \mathrm{i}}=\frac{\mathrm{V}_{\mathrm{t}, \mathrm{i}}}{\mathrm{Q}_{\mathrm{t}, \mathrm{i}}}
$$

where $\mathrm{V}_{\mathrm{t}, \mathrm{i}}$ - the amount of energy consumed in the production process;

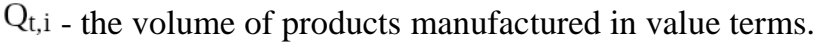

In this study, only a separate aspect of this effect in terms of electricity will be considered.

\section{Findings}

The calculation pursuant to formulas (2) and (3) was made on the basis of data from official statistical collections in the context of the regions of the Central Federal District.

The results are shown in Tables 1 and 2.

Table 1. Resource decoupling (d)

\begin{tabular}{|c|c|c|c|c|c|c|}
\hline & & $\mathbf{2 0 1 5}$ & $\mathbf{2 0 1 6}$ & $\mathbf{2 0 1 7}$ & $\mathbf{2 0 1 8}$ & $\mathbf{2 0 1 9}$ \\
\hline $\begin{array}{c}\text { Russian } \\
\text { Federation }\end{array}$ & & 0.000104 & 0.000299 & -0.002870 & 0.002115 & 0.000633 \\
\hline CFD & & -0.000419 & 0.000182 & -0.003145 & 0.000805 & 0.000538 \\
\hline Belgorod region & $\# 1$ & 0.004296 & -0.002756 & 0.000712 & -0.001867 & -0.000070 \\
\hline Bryansk region & $\# 2$ & 0.003245 & -0.000193 & 0.006734 & 0.004766 & 0.002510 \\
\hline Vladimir region & $\# 3$ & -0.003718 & 0.000020 & 0.004236 & 0.000004 & -0.002008 \\
\hline Voronezh region & $\# 4$ & 0.001461 & -0.000135 & -0.001114 & -0.006557 & -0.000109 \\
\hline Ivanovo region & $\# 5$ & -0.004845 & 0.000887 & -0.012423 & 0.000249 & 0.030989 \\
\hline Kaluga region & $\# 6$ & 0.000466 & 0.004626 & 0.005888 & 0.000792 & 0.005664 \\
\hline Kostroma region & $\# 7$ & -0.001076 & 0.000619 & 0.000707 & 0.013950 & -0.004861 \\
\hline Kursk region & $\# 8$ & 0.002877 & -0.002504 & -0.001914 & -0.001458 & 0.000281 \\
\hline Lipetsk region & $\# 9$ & -0.000200 & 0.000992 & -0.000264 & 0.004409 & -0.000006 \\
\hline Moscow region & $\# 10$ & -0.000513 & 0.000025 & -0.001600 & 0.004432 & 0.005763 \\
\hline Oryol region & $\# 11$ & -0.000294 & 0.001327 & -0.000005 & -0.001172 & 0.003289 \\
\hline Ryazan region & $\# 12$ & -0.000058 & 0.000694 & -0.002955 & -0.000067 & -0.003109 \\
\hline Smolensk region & $\# 13$ & -0.000208 & 0.000736 & -0.000031 & 0.010614 & 0.000048 \\
\hline Tambov region & $\# 14$ & -0.001111 & 0.000110 & 0.001333 & -0.000011 & -0.002538 \\
\hline Tver region & $\# 15$ & 0.000186 & 0.000698 & 0.019229 & -0.006107 & -0.010975 \\
\hline Tula region & $\# 16$ & 0.012480 & -0.000471 & -0.000848 & 0.002104 & 0.000570 \\
\hline Yaroslavl region & $\# 17$ & 0.007517 & -0.001511 & -0.006143 & 0.002927 & 0.001507 \\
\hline Moscow & $\# 18$ & 0.000211 & 0.000036 & -0.006808 & -0.002117 & 0.000063 \\
\hline
\end{tabular}

Estimating the obtained values, it becomes possible to draw a number of conclusions:

- at the beginning of the analyzed period - 2015 - there was no effect of resource decoupling, which indicates similar trends in economic development and environmental burden in 9 out of 18 subjects of the Central Federal District. In 2018, the number of such regions decreased and amounted to 8 . In other regions, there is a mismatch in the trends of the economic and environmental components.

- at the national level, the effect of resource decoupling was absent only in 2017, at the district level - in 2015 and 2017.

Table 2. Impact decoupling (E)

\begin{tabular}{|l|l|l|l|l|l|l|}
\hline & & 2015 & 2016 & 2017 & 2018 & 2019 \\
\hline
\end{tabular}




\begin{tabular}{|c|c|c|c|c|c|c|}
\hline Russian Federation & & 0.000018 & 0.000016 & 0.000016 & 0.000015 & 0.000013 \\
\hline CFD & & 0.000011 & 0.000010 & 0.000009 & 0.000009 & 0.000008 \\
\hline Belgorod region & $\# 1$ & 0.000001 & 0.000001 & 0.000001 & 0.000001 & 0.000001 \\
\hline Bryansk region & $\# 2$ & 0.000000 & 0.000001 & 0.000000 & 0.000000 & 0.000000 \\
\hline Vladimir region & $\# 3$ & 0.000006 & 0.000006 & 0.000005 & 0.000003 & 0.000004 \\
\hline Voronezh region & $\# 4$ & 0.000021 & 0.000018 & 0.000020 & 0.000021 & 0.000019 \\
\hline Ivanovo region & $\# 5$ & 0.000012 & 0.000009 & 0.000012 & 0.000008 & 0.000007 \\
\hline Kaluga region & $\# 6$ & 0.000001 & 0.000001 & 0.000001 & 0.000001 & 0.000001 \\
\hline Kostroma region & $\# 7$ & 0.000112 & 0.000093 & 0.000097 & 0.000099 & 0.000078 \\
\hline Kursk region & $\# 8$ & 0.000103 & 0.000092 & 0.000079 & 0.000077 & 0.000061 \\
\hline Lipetsk region & $\# 9$ & 0.000013 & 0.000012 & 0.000011 & 0.000010 & 0.000009 \\
\hline Moscow region & $\# 10$ & 0.000009 & 0.000007 & 0.000006 & 0.000006 & 0.000005 \\
\hline Oryol region & $\# 11$ & 0.000007 & 0.000005 & 0.000006 & 0.000006 & 0.000006 \\
\hline Ryazan region & $\# 12$ & 0.000028 & 0.000020 & 0.000021 & 0.000015 & 0.000012 \\
\hline Smolensk region & $\# 13$ & 0.000114 & 0.000106 & 0.000095 & 0.000089 & 0.000069 \\
\hline Tambov region & $\# 14$ & 0.000004 & 0.000003 & 0.000004 & 0.000004 & 0.000003 \\
\hline Tver region & $\# 15$ & 0.000124 & 0.000129 & 0.000102 & 0.000107 & 0.000098 \\
\hline Tula region & $\# 16$ & 0.000015 & 0.000012 & 0.000012 & 0.000009 & 0.000008 \\
\hline Yaroslavl region & $\# 17$ & 0.000008 & 0.000007 & 0.000008 & 0.000012 & 0.000012 \\
\hline Moscow & $\# 18$ & 0.000004 & 0.000003 & 0.000004 & 0.000003 & 0.000003 \\
\hline
\end{tabular}

Assessing the impact decoupling, it should be noted that this indicator increased over the analyzed period only in three regions: in Bryansk $(+31 \%)$ and Yaroslavl $(+52 \%)$ regions. Herewith, the lowest electrical capacity is still observed in the Bryansk region. The rest of the subjects showed a decrease in this indicator. A similar trend may be traced both at the district $(-31 \%)$ and national $(-27 \%)$ levels. The largest decrease is observed in Kaluga $(-52 \%)$, Kostroma (-52\%) and Ryazan (-58\%) regions.

To simplify the identification of features, scatter diagrams were constructed (Figs. 1 and 2) for 2015 and 2019.

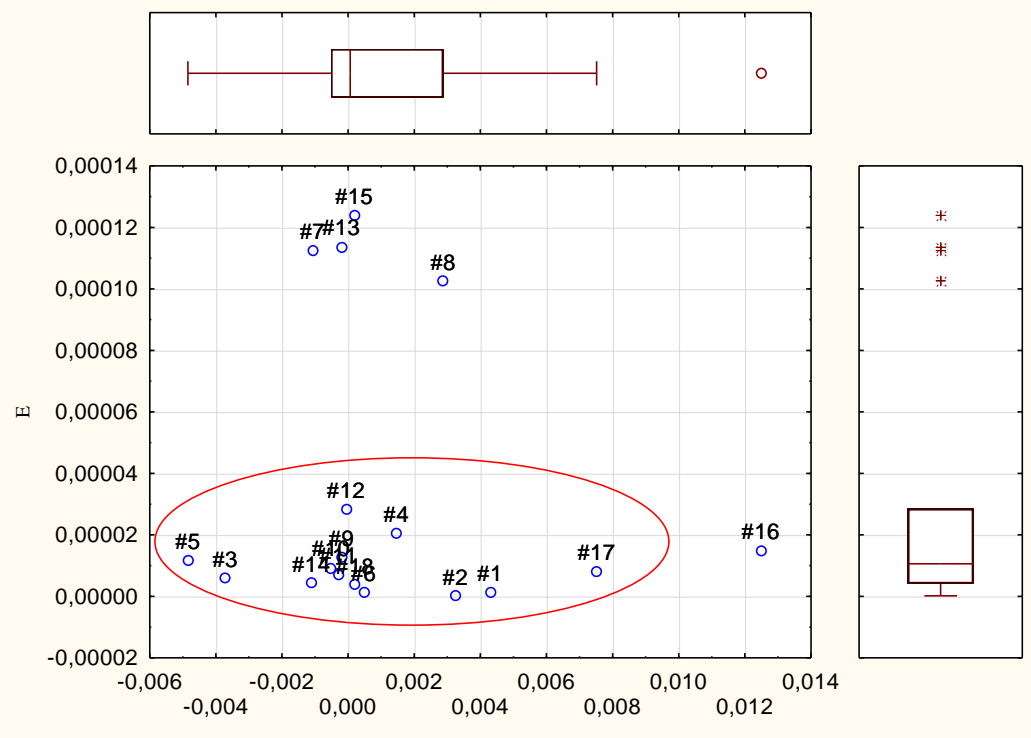

Fig. 1. Dispersion chart, 2015.

In 2015, it may be noted that five regions do not fit into the general trend: Kostroma, Kursk, Smolensk, Tver, Tula regions. 


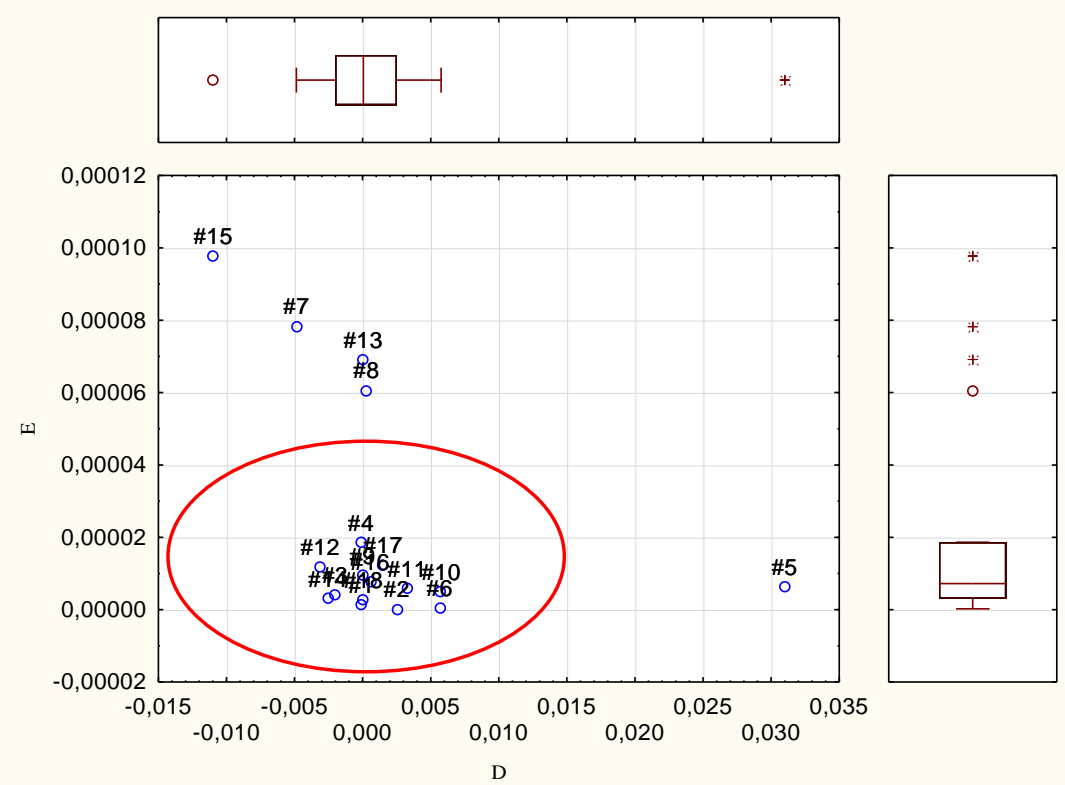

Fig. 2. Dispersion chart, 2019.

In 2019, the number of such regions remains constant, but the structure is changing: Ivanovo, Kostroma, Kursk, Smolensk and Tver regions.

Evaluating the changes that have taken place, it becomes possible to draw a conclusion about the decrease in interregional differentiation and the alignment of trends in both economic and environmental development.

However, the stability of these processes should be assessed separately. It becomes possible to perform the analysis using the indicator of variation $(\mathrm{V})$.

$$
\begin{gathered}
\mathrm{V}=\frac{\sigma}{\mathrm{k}} \\
\text { at } \sigma=\sqrt{\frac{1}{\frac{1}{\mathrm{n}} \sum_{\mathrm{i}=1}^{\mathrm{n}}\left(\mathrm{k}_{\mathrm{i}}-\mathrm{k}\right)^{2}}}
\end{gathered}
$$

where $\sigma-$ a mean square deviation;

$\mathrm{k}$ - mean data row value;

$\mathrm{n}$-the number of periods for which the data are presented.

The interpretation of this indicator is adopted pursuant to the general theory of statistics [31], ie the process is:

- steady at $\mathrm{V} \leq 0.1$;

- sufficiently stable if $\mathrm{V}$ ranges within $0.1-0.2$;

- quite unstable if $\mathrm{V}$ ranges within 0.21 - 0.33 ;

- unstable at $\mathrm{V} \geq 0.34$.

The data obtained as a result of assessing the $\mathrm{d}$ and $\mathrm{E}$ indicators by the type of resistance is presented in Table 3 .

Table 3. Analysis of stability in terms of $d$ and $E$.

\begin{tabular}{|c|c|c|c|c|}
\hline & d, coefficient & $\begin{array}{c}\text { Characteristic of } \\
\text { process }\end{array}$ & E, coefficient & $\begin{array}{c}\text { Characteristic of } \\
\text { process }\end{array}$ \\
\hline Russian & 20.88 & unstable & 0.09 & stable \\
\hline
\end{tabular}




\begin{tabular}{|c|c|c|c|c|}
\hline Federation & -2.70 & unstable & 0.10 & rather stable \\
\hline $\begin{array}{c}\text { CFD } \\
\text { Belgorod } \\
\text { region }\end{array}$ & 30.94 & unstable & 0.06 & stable \\
\hline $\begin{array}{c}\text { Bryansk } \\
\text { region }\end{array}$ & 0.55 & unstable & 0.69 & unstable \\
\hline $\begin{array}{c}\text { Vladimir } \\
\text { region }\end{array}$ & -7.01 & unstable & 0.17 & rather stable \\
\hline $\begin{array}{c}\text { Voronezh } \\
\text { region }\end{array}$ & -1.63 & unstable & 0.06 & stable \\
\hline $\begin{array}{c}\text { Ivanovo } \\
\text { region }\end{array}$ & 3.77 & unstable & 0.21 & unstable enough \\
\hline Kaluga region & 0.66 & unstable & 0.22 & unstable enough \\
\hline $\begin{array}{c}\text { Kostroma } \\
\text { region }\end{array}$ & 2.59 & unstable & 0.08 & stable \\
\hline Kursk region & -3.12 & unstable & 0.15 & rather stable \\
\hline Lipetsk region & 1.39 & unstable & 0.10 & stable \\
\hline $\begin{array}{c}\text { Moscow } \\
\text { region }\end{array}$ & 1.72 & unstable & 0.19 & rather stable \\
\hline Oryol region & 2.14 & unstable & 0.08 & stable \\
\hline Ryazan region & -1.41 & unstable & 0.24 & unstable enough \\
\hline $\begin{array}{c}\text { Smolensk } \\
\text { region }\end{array}$ & 1.50 & unstable & 0.13 & rather stable \\
\hline $\begin{array}{c}\text { Tambov } \\
\text { region }\end{array}$ & -2.49 & unstable & 0.08 & stable \\
\hline Tver region & 12.35 & unstable & 0.10 & stable \\
\hline Tula region & 1.40 & unstable & 0.19 & rather stable \\
\hline $\begin{array}{c}\text { Yaroslavl } \\
\text { region }\end{array}$ & 4.36 & unstable & 0.23 & unstable enough \\
\hline Moscow & -1.27 & unstable & 0.08 & stable \\
\hline
\end{tabular}

\section{Discussion}

Evaluating the data obtained, we note that the stability of the processes by the parameter of resource decoupling (d) is unsatisfactory for all analyzed territories at all levels: national, district and regional. Pursuant to the parameter of decoupling of the effect (E), the tendencies differ. At the country level, the process is stable, which is confirmed by the obtained coefficient of variation (0.09). The indicator at the CFD level differs slightly in magnitude (0.10), however, pursuant to the scale adopted in the study, it may already be classified as "sufficiently stable". All voiced categories are represented among the regions. The largest group is the group of subjects that have demonstrated the sustainability of the process being assessed: Belgorod, Voronezh, Kostroma, Lipetsk, Oryol, Tambov, Tver regions, Moscow. Next comes the category "Sufficiently stable": Vladimir, Kursk, Moscow, Smolensk, Tula regions; and "Unstable enough": Kaluga, Ivanovo, Ryazan and Yaroslavl regions. The group of territories with processes characterized as unstable is represented only by the Bryansk region.

Despite the revealed decrease in differentiation pursuant to the $\mathrm{d}$ and $\mathrm{E}$ criteria, there is still a significant stratification pursuant to the latter of them. This fact is explained by the current mismatch arising due to the actual stability of the ongoing processes. Accordingly, in order to further reduce the differentiation of territories by the factors being analyzed, it is necessary to ensure the sustainability of development models. 


\section{Conclusion}

Based on the study, assessing the factors that are designed to ensure the sustainability of development and characterize its presence, the fundamental elements should be highlighted: consistent economic growth of the entire national economy of the region, the obligatory social orientation of the economy and the observance of the principle of environmental protection of nature to comply with the primordial interests of existing and future generations. Herewith, it should be noted that the key to sustainable development of the region may only be its aspirations to develop and implement modern innovations based on the use and creation of digital technologies while reducing the use of fossil fuels and the use of more advanced types of energy.

However, while assessing the coordinated economic development of territories in the era of digitalization and the accompanying dynamics of the environmental load, it should be noted that in a number of regions there are problems in the inconsistency of these aspects.

A further research direction may be the identification of the reasons for differentiation, as well as analyzing the reasons for the mismatch between the economic and environmental components of the process of sustainable development of subjects.

\section{References}

1. T.V. Uskova, Problems of Territorial Development 2, 7 (2020). DOI: 10.15838/pti. 2020.2.106.1.

2. S. Zemtsov, V. Barinova, V. Kidyaeva, T. Panshina, Economic Policy 15(2), 18 (2020). DOI: 10.18288/1994-5124-2020-2-18-47.

3. E.S. Gubanova, V.S. Kleshch, Economic and social changes: facts, trends, forecast $\mathbf{1 2}$ (5), 44 (2019). DOI: 10.15838/esc. 2019.5.65.3.

4. K.N. Yusupov, Yu.S. Toktamysheva, A.V. Yangirov, R.R. Akunov, Regional Economy 15 (1), 151 (2019). DOI: 10.17059/2019-1-12.

5. J. Stiglitz, A. K. Sen, Y.P. Fitoussi, The Measurimentop Economic Perfomanse and Social Progress Revisited: Reflections and Overview, Paris (2009)

6. Y. Horbach Rammerc, K. Renngs, Ecological Economics 78, 112 (2012)

7. R. Gomez-Colvet, D. Conesa, A. Gomez-Colvet, E. Tormosa-Ausina, Applied Energy 132, 137 (2014)

8. N. Davidson, O. Mariev, A. Pushkarev, Foresight and STI Governance 12 (3 (62) (2018). DOI: 10.17323/2500-2597.2018.3.62.72.

9. V.V. Stepanova, A.V. Ukhanova, A.V. Grigorishchin, D.B. Yakhyaev, Economic and social changes: facts, trends, forecast 12 (2), 73 (2019). DOI: 10.15838/esc.2019.2.62.4.

10. M. Fritsch, M. Wyrwich, Foresight and STI Governance 12 (2), 62 (2019). DOI: 10.17323/2500-2597.2019.2.62.71.

11. B.T. Asheim, M.S. Gertler, The Oxford Handbook of Innovation. Eds. J. Fagerberg, D.C. Mowery, R.R. Nelson, Oxford: Oxford University Press, 291 (2006). https://doi.org/10.1093/ oxfordhb/9780199286805.003.0011.

12. D. Abuzyarova, V. Belousova, Zh. Krayushkina, Y. Lonshcikova E. Nikiforova, N. Chichkanov, Foresight and STI Governance 13 (2), 107 (2019). DOI: 10.17323/25002597.2019.2.107.119. 
13. S. Zemtsov, V. Barinova, R. Semenova, Foresight and STI Governance 13 (2), 84 (2019). DOI: 10.17323/25002597.2019.2.84.96.

14. A. Sorgner, Foresight and STI Governance 11 (3), 37 (2017). DOI: 10.17323/25002597.2017.3.37.48.

15. T. Berger, C.B. Frey, Regional Science and Urban Economics 57, 38 (2016)

16. E.Z. Zinder, Business Informatics 3 (45), 7 (2018)

17. A. Golwan, el al., Designing value-oriented servisesistemsbu value map. Proceedings of the International Simposium on BusinesMedeling and SoltwareDesing (BMSD 2013), Noordwijkernhoud, Nethelands, 8-10 July 2013. Lecture Notes in Busines Information Processing 173, 150 (2014)

18. V.I. Ananyin, K.V. Zimin and M.I. Lugachev, R.D. Gimranov, K.G. Skripkin, Business Informatics 2, 45 (2018)

19. 19.V. Nissen, T. Lezina, A. Saltan, Foresight and STI Governance 12 (3), 53 (2018). DOI: 10.17323/2500-2597.2018.3.53.61.

20. T. A. Byrd, D.E. Turner, Decision Sciences 32 (1), 21 (2001)

21. YU.V. Turovets, K.O. Vishnevsky, Business Informatics 13 (3), 78 (2019)

22. V.L. Makarov, A.R. Bakhtizin, G.L. Beklaryan, Business Informatics 13 (4), 7 (2019)

23. B. A. Talkehestani et al., Automatisierungstechnik 67 (9), 762 (2019). DOI: 10.1515/auto-2019-0039.

24. P. Rucker Schaeffer, B. Fischer, S. Queiroz, Foresightand STI Governance 12 (2), 50 (2018). DOI: 10.17323/2500-2597.2018.2.50.61.

25. E.A. Prokopiev, A.E. Kurilo, O.V. Gubina, Economic and social changes: facts, trends, forecast 12 (5), 76 (2019). DOI: 10.15838/esc.2019.5.65.5.

26. 25 S. Plaksin, G. Abdrakhmanova, G. Kovaleva, Foresight and STI Governance 11 (1), 55 (2017). DOI: 10.17323/2500-2597.2017.1.55.65.

27. E. Kutsenko, Y. Eferin, Foresight and STI Governance 13 (3), 24 (2019). DOI: 10.17323/2500-2597. 2019.3. 24.40.

28. I.V. Grebenkin, Regional Economy 16 (1), 69 (2020). DOI. org/10.17059/2020-1-6.

29. V. Milovicov, Foresight and STI Governance 13 (1), 62 (2019) DOI: 10.17323/25002597.2019.1.62.68.

30. S.N. Bobylev, V.M. Zakharov, Towards Russia's Sustainable Development: Bulletin 60, 89 (2012)

31. Decoupling natural resource use and environmental impacts from economic growth. UNEP, (2011). http: // www.gci.org.uk/Documents/Decoupling_Report_English.pdf

32. V. V. Polyakova, N. V. Shabrova, Fundamentals of the theory of statistics: textbook. allowance, Ministry of Education and Science Ros. Federation, 2nd ed., Rev. and add. Yekaterinburg: UrFU Publishing House, 148 p. (2015) 